\title{
Technique of Renal Homotransplantation
}

\author{
Experience With 42 Cases
}

THOMAS E. STARZL, MD; THOMAS L. MARCHIORO, MD; THEODORE C. DICKINSON, MD; DAVID RIFKIND, MD; OLIVER G. STONINGTON, MD; AND WILLIAM R. WADDELL, MD, DENVER

Purely technical considerations play an important role in successful renal homotransplantation. Minimization of homograft ischemia is critical. Additional important factors involve the site of placement of the homograft, provision for unkinked vascular channels, selection of a method of ureteroneocystostomy which permits early removal of the urethral catheter, and use of a onestage operation incorporating bilateral nephrectomy and splenectomy in addition to homotransplantation.

In the present study, the methods used to meet these purely surgical requirements will be described as they have evolved in the course of caring for the first 42 patients treated with renal homografts from living donors. Consideration will not be given to patients receiving cadaveric kidneys ${ }^{1}$ or two who received homografts from identical twins, ${ }^{2}$ since the circumstances in such cases are different than those which obtained with our major experience.

The prerequisites and techniques of the donor operation have recently been fully doc-

Read before the 21st Annual Meeting of the Central Surgical Association, Rochester, Minn, Feb 27-29, 1964

Markle Scholar (Dr. Starzl).

From the departments of surgery and medicine, University of Colorado Medical Center and Veterans Administration Hospital.

Aided by grants A-6283, A-6344, HE 07735, AM 07772, AI041542, and OG 27 from the United States Public Health Service.

Staral et al umented by Marchioro and his associates. It should be noted that the homograft is cooled and heparinized in every case in order to minimize the ischemic injury during transfer of the kidney. ${ }^{3}$ The following description will treat only of the procedures which are directly applied to the recipient patient.

\section{Surgical Techniques}

General Considerations.-A description of the surgical techniques employed involves considerably more than just the homografting procedure, since bilateral nephrectomy and splenectomy are an integral part of the total therapy, and are usually performed at the same time as homotransplantation (Table 1). The additional adjuvant procedure of thymectomy" which was used in eight patients early in the series has been discontimued, at least until long term follow ups are obtained on those patients already so treated.

The technical problems are no different from those encountered in any major surgical operation. Nevertheless, the predictably poor healing processes, caused by the metabolically depleted state of the

TABLE 1.-Comparison of Results with Staged Versus One-Stage Surgical Treatment *

\begin{tabular}{lccc}
\hline \hline & No. & Allve & Dead \\
Ono-8tage & 81 & 10 & 12 \\
Two or more stages & 11 & 5 & 6 \\
& $\frac{1}{4}$ & $\frac{14}{18}$
\end{tabular}

- All patients had trangplantation 96 daye or longer pilor to Feb 27, 1994. The sverage survival in the Uifing patiente is 217 days, randing trom 08 to 401 . The averace survival of those who died was 60 dags, with a range of 1 to 206. 


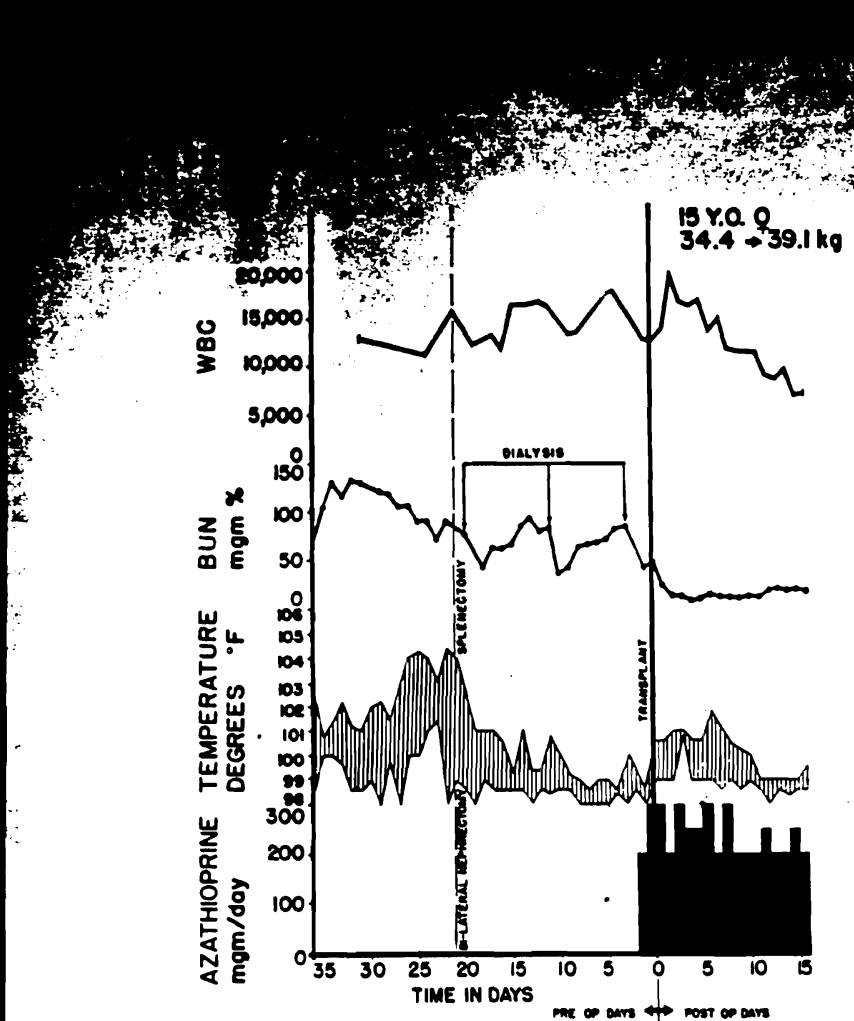

Fig 1.-Course of a patient who received staged surgical care because of urinary tract infection. The child had polycystic kidney disease with coliform and fungal infection within multiple cysts of each kidney. Bilateral nephrectomy and splenectomy were carried out at a first stige, rcsulting in prompt relief of the preexisting hyperpyrexia. Three weeks later, renal transplantation was performed. She is now eight months postoperative.

patients and by the necessity for immunosuppressive therapy, reduce the margin of safety which may permit success in other operations in spite of the commission of small errors. It is mandatory to obtain primary wound healing. Wound drains or cystostomies are never used, and urethral catheters which are inserted at the time of operation are extracted within 24 hours.

Interrelationship of Operation and Incivions.Originally it was thought that multiple operations would be required, but subsequent experience has shown that this is not the case. Bilateral nephrectomy, splenectomy, and homotransplantation are well tolerated in one stage (Table 1), and unless there is a specific contraindication, this is the method now used except for those patients in whom an upper urinary tract infection is present. In the latter circumstances, splenectomy and bilateral nephrectomy are carried out initially (Fig 1), and transplantation is performed two or three weeks later after good wound healing from the original operation has occurred.

A variety of exposures have been used for patiegts receiving one-stage therapy, depending in o. - to thon the location planned for the homo-

ingon the location planned for the homoinf upper midline incision, through

which both kidneys and spleen are removed transperitoneally, in combination with an extraperitoneal transplantation to either the right or left iliac fossa (Fig 2C). If transplantation is planned of a donor left kidney to the right iliac fossa, both transplantation and right nephrectomy can be done extraperitoneally through an oblique right lower abdominal incision, and left nephrectomy and splenectomy performed transperitoneally through a separate left subcostal incision (Fig 2A). In transplanting a donor right kidney to the left iliac fossa, three incisions may be used-one for the extraperitoneal transplantation, another for transperitoneal left nephrectomy and splenectomy, and a third for either extra or intraperitoneal right nephrectomy (Fig $2 B$ ). In three children of 3 to 8 years, the entire operation was performed transperitoneally through a total midline abdominal incision (Fig $2 D$ ), using relatively oversized homografts from adult donors.

Itomotransplantation.-The donor kidneys are usually but not necessarily placed in the contralateral iliac fossa after the method described by Küss, ${ }^{7}$ and popularized by Murray and Harrison " and Hume.' The anteroposterior rclationships of the hilar structures are thereby usually reversed, placing the pelvis anteriorly and the renal vein posteriorly in the new location. There are no important differences in technique with transplantation to one as opposed to the other side, so the following description in which the homograft is placed on the right applies equally to the comparable operation on the left. In the usual case, the splenectomy and nephrectomies have already been completed as described above, and the upper abdominal incision or incisions have been closed. In four cases, donor right kidneys were placed in the right iliac fossa with good results, so the use of contralateral homografts as described below is not mandatory. Deviations from the standard technique to be described constitute a special problem, and have been described in detail elsewhere.

An oblique lower abdominal incision is made, and deepened to the extraperitoneal plane (Fig 3 and 4). The inferior epigastric vessels (Fig $4 C$ ) and the spermatic cord (Fig 4D) are quadruply ligated and divided. If the recipient's right kidney is to be removed through this incision, this is done now.

The lymphatic and areolar tissue overlying the external iliac vein is incised, ligating all filaments of tissue (Fig $5 E$ ) in order to prevent postoperative lymph leakage. The presence of valves in the external iliac vein is noted, and when possible the venous anastomosis is performed either above or below these structures. If this is inconvenient, the valves are excised at the time of the anastomosis. ${ }^{20}$ The hypogastric artery is then denuded of surrounding tissue and cleaned to the point of its first division (Fig $5 F$ and $5 G$ ). Since kidneys are no longer used which do not have a single renal artery," dissection.

Dol $89, J$ uly, 196t

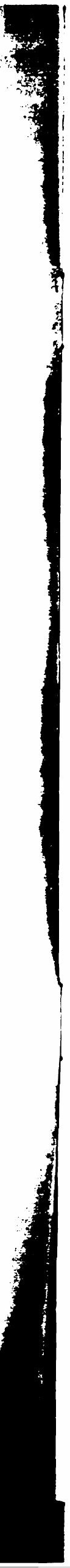




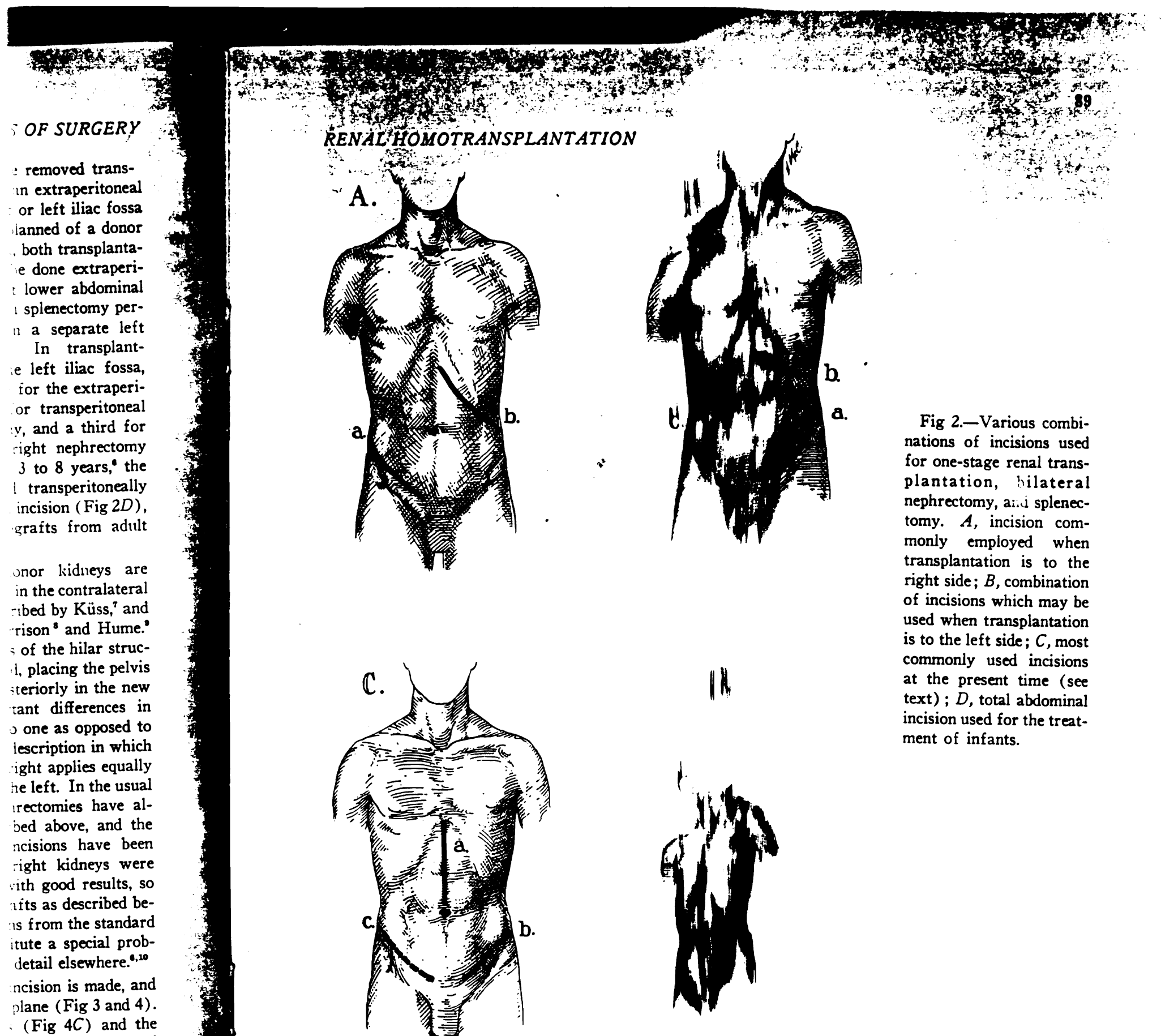

(Fig 4C) and the quadruply ligated -ight kidney is to be this is done now.

issue overlying the ating all filaments of revent postoperative of valves in the ex$i$ when possible the ned either above or is inconvenient, the of the anastomosis. ${ }^{10}$ lenuded of surroundint of its first division vs are no longer used :al artery," dissection,

Vol 89, July,

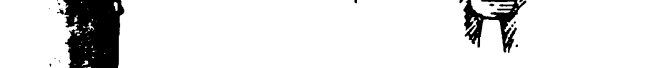

of the branches of the hypogastric artery for that in multiple vessel anastomoses is not necessary.

When it has been ascertained that the donor kfll ney will be available within a few minutes, a pot. tion of the external iliac vein is isolated betwetill Brown " * sponge rubber, noncrushing clamps ( $H$. $6 A$ and $6 B$ ). A disc of tissue is excised from thl anterolateral wall of the vessel (Fig $6 B$ ) and thit stay sutures of 5-0 arterial silk are placed (F) $6 C)$. Exposure is maintained and all activity siff. pended until arrival of the kidney.
11 |ll| the kidney is delivered, it is oriented in the II $\|$ Ilfamic position as existed in the donor paNill f i is $6 C$ ). The previously placed guide sutures Ifllillod to the appropriate portions of the renal IIIII the kidney is guided into position until the ilill Ayers of the two vessels are coapted (Fig Wilia kidney is then rolled laterally and a UI Iay suture placed in the midportion of the 11. Wall of the renal vein (Fig 7E). Traction Hilial and lateral stay sutures helps in preHecidental grasping of the opposite wall 1. Inp farming the venous anastomosis. One of wille sutures is then used to perform a conII nnatomosis using an over-and-over tech-

\section{Edward Weck \& Co., Long Island, NY.}




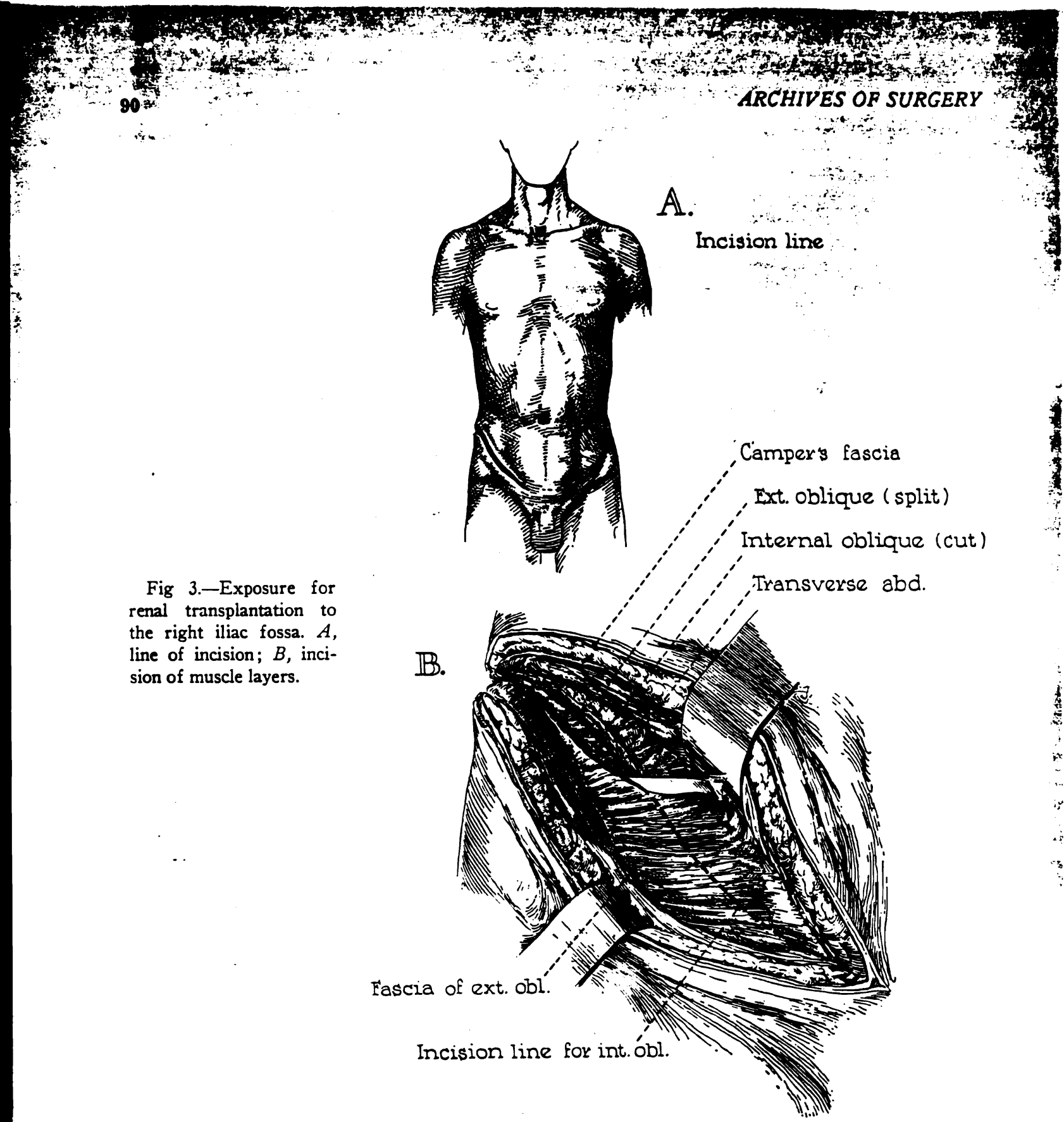

nique. It is usually easier to sew the anterior row first, then reflecting the kidney medially in order to obtain access to the posterior surface (Fig $7 E$ and $7 F)$.

After completion of the venous anastomosis, the kidney is placed into what appears to be the most comfortable position in the iliac fossa. The distal hypogastric artery is ligated at this time, and after placement of a noncrushing clamp across the origin of this vessel from the common iliac artery, it is transected. The cut is made with an angulation (Fig 84) to allow the subsequent formation of a smooth 1. Cone at the site of anastomosis. After placement of H. In mutures in the hypogastric and renal arteries

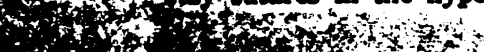

(Fig $8 B$ ), an anastomosis is performed with $6-0$ silk, using a continuous everting technique (Fig 8C-E).

After completion of both anastomoses, the clamps are released, taking care that arterial and venous occlusion are relieved simultaneously. The clamps are released abruptly rather than in a graduated fashion. The suture lines are scrutinized for leak and are systematically repaired with additional sutures. Under no circumstances is the blood supply to the kidney ever interrupted again. It is always possible to repair the small suture line leaks without reoccluding the circulation.

Vol 89, July, 1964 


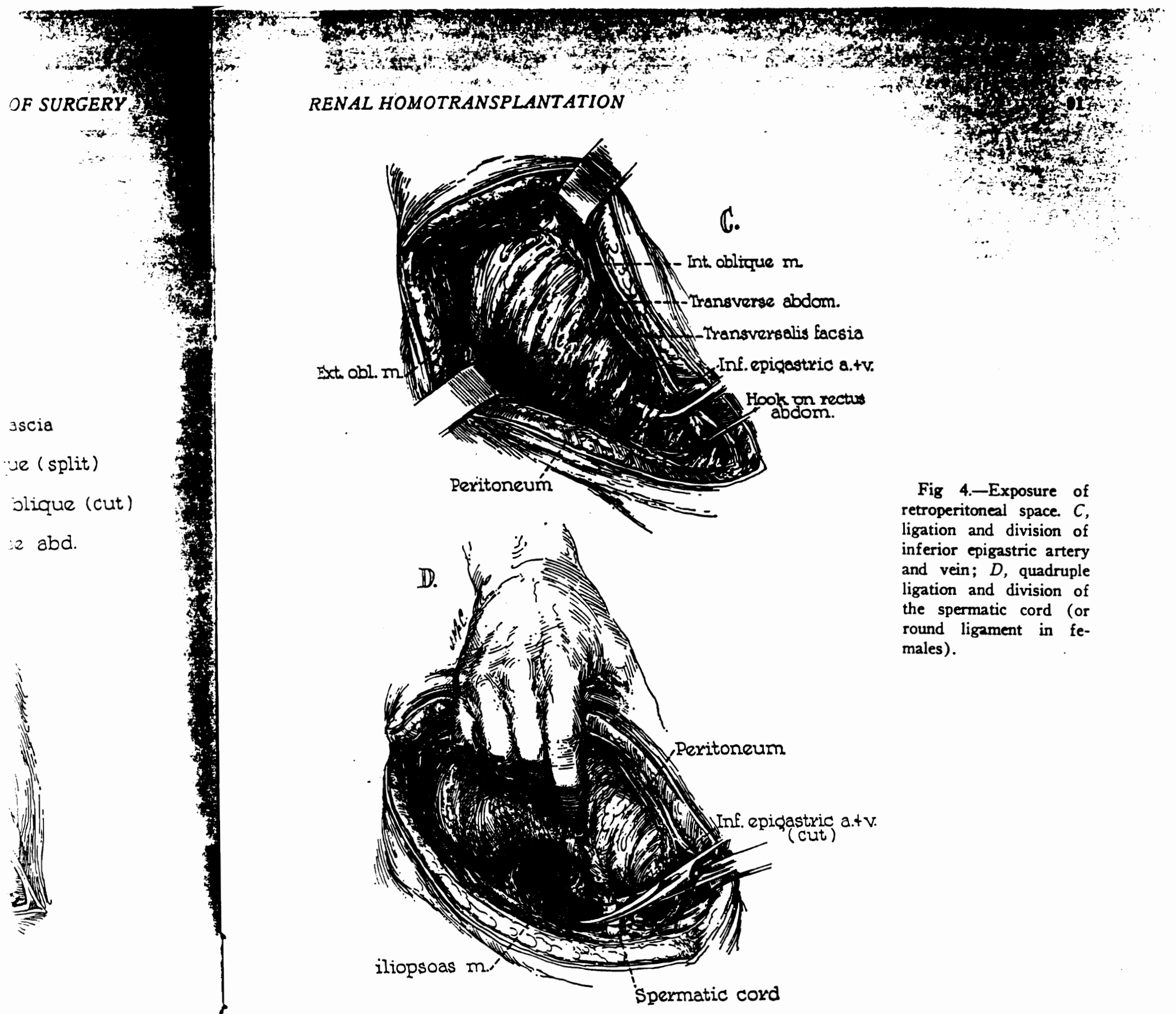

rformed with 6-0 erting technique

umoses, the clamps rial and venous ocy. The clamps are graduated fashion. for leak and are tional sutures. Unrod supply to the : is always possible caks without reoc-

iol 89, July, 1964.
At this time, experimentation is again conducted to determine the most comfortable position of the homograft. The most consistently useful rule to be followed is that the kidney will usually seek the position which is most suitable. A location which requires extensive capsular fixation is not desirable, and no restraining sutures of any sort are used to prevent movement. The ultimate location of the kidney has varied considerably (Fig 9). Usually the hollow of the ilium is adequate to accommodate the organ, but in some cases, most or all of the homograft is extrapelvic.

Having settled the location of the homograft, the ureter is anastomosed to the bladder by a modification of the method of Pacquin and Marshall." As

Starsl et al little mobilization of the bladder as possible is carried out. If possible, the retropubic space is not entered, thereby preventing the formation of a postoperative dead space. A small incision is made in the dome of the bladder near the peritoneal reflection. By appropriate manipulation of thin-bladed deep retractors, an adequate view can be obtained of the interior of the bladder (Fig 10A).

A site is selected 2 or $3 \mathrm{~mm}$ above the ipsilateral ureteral orifice for the location of the new ureteral tip. After making a small mucosal incision at this point, a similar counterincision is made 1 or $2 \mathrm{~cm}$ higher on the lateral wall (Fig 10B), and the intervening mucosa is tunneled by blunt hemostat dissection (Fig 10C). A right angle clamp is then 


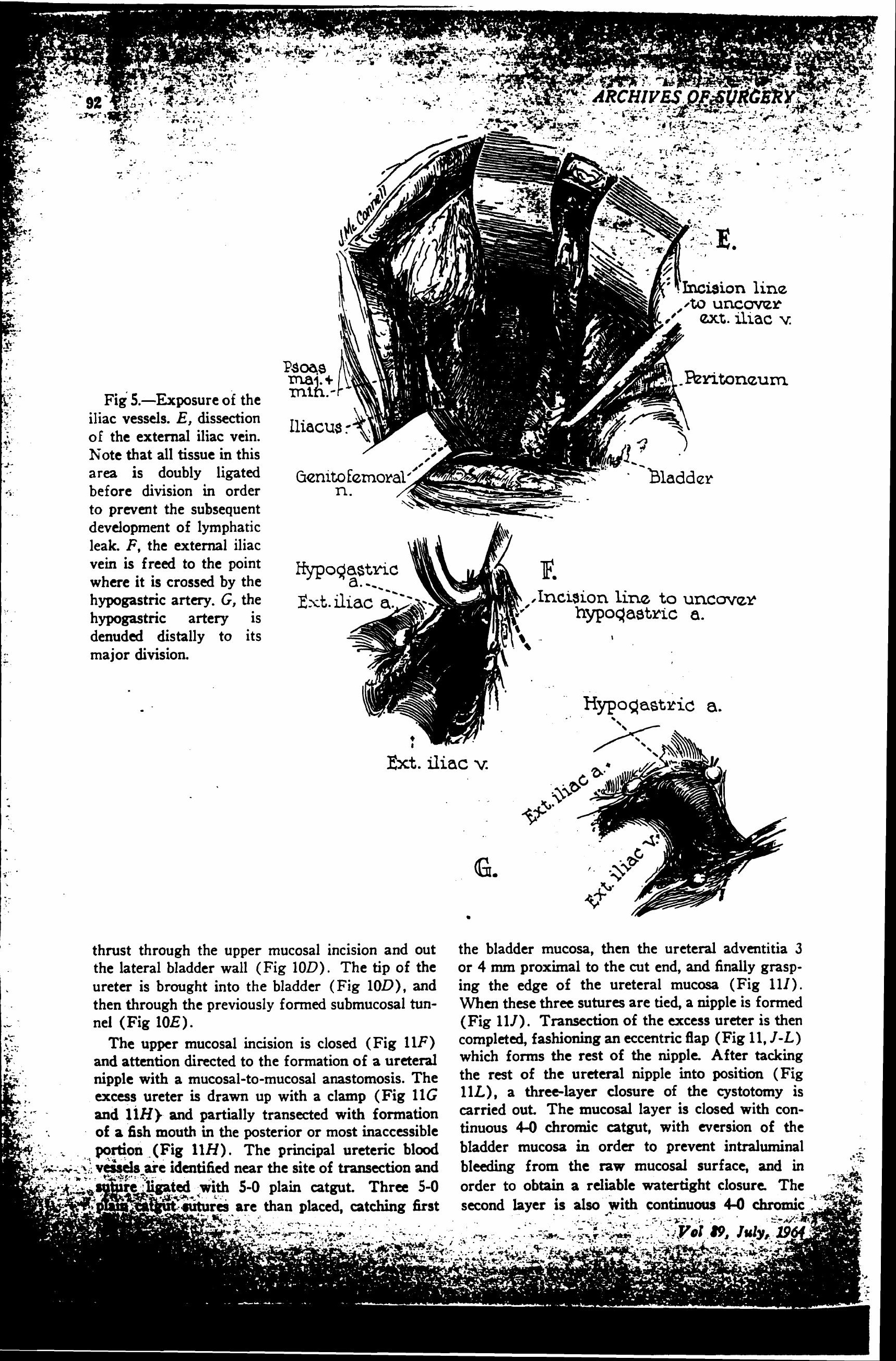




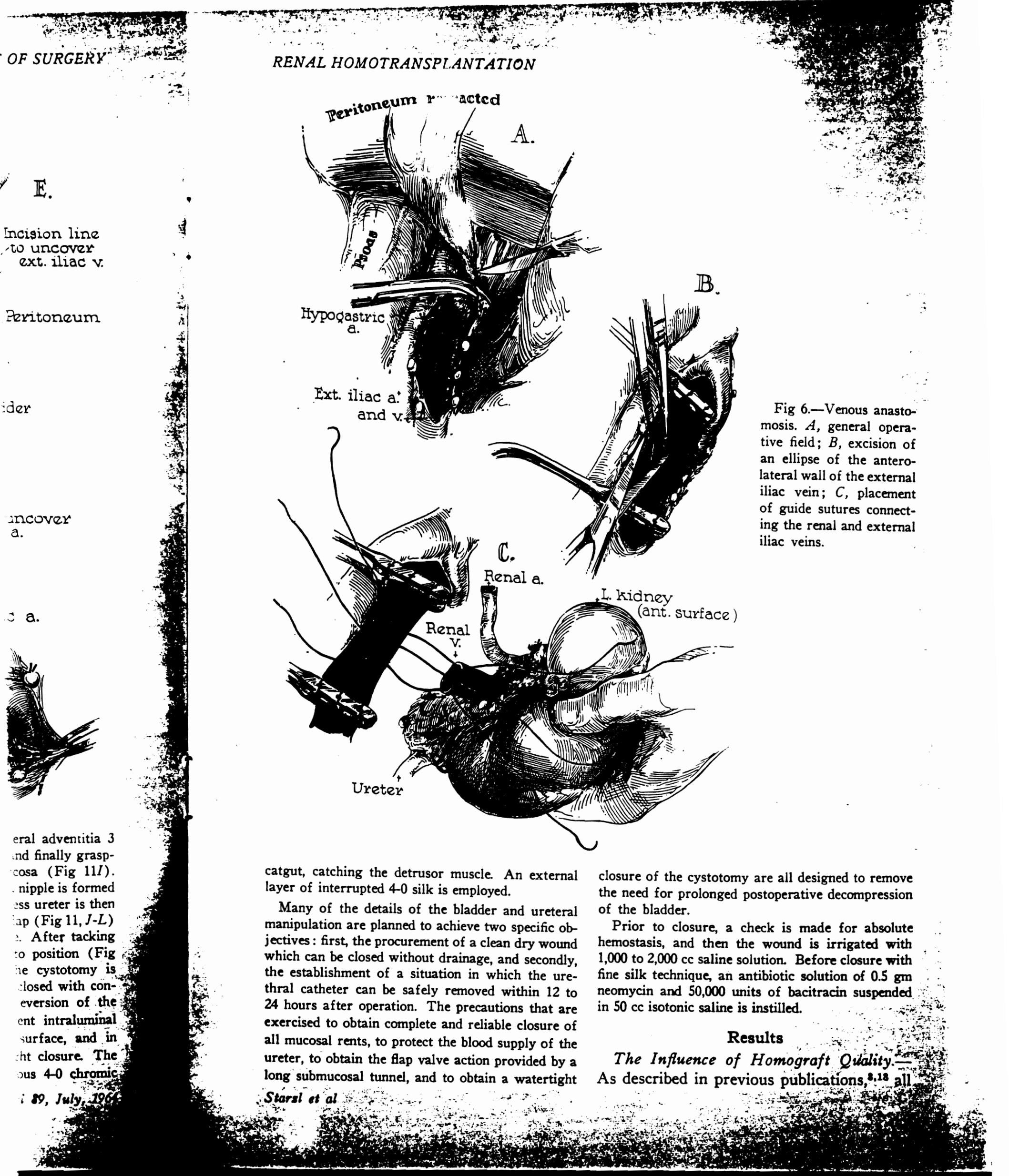




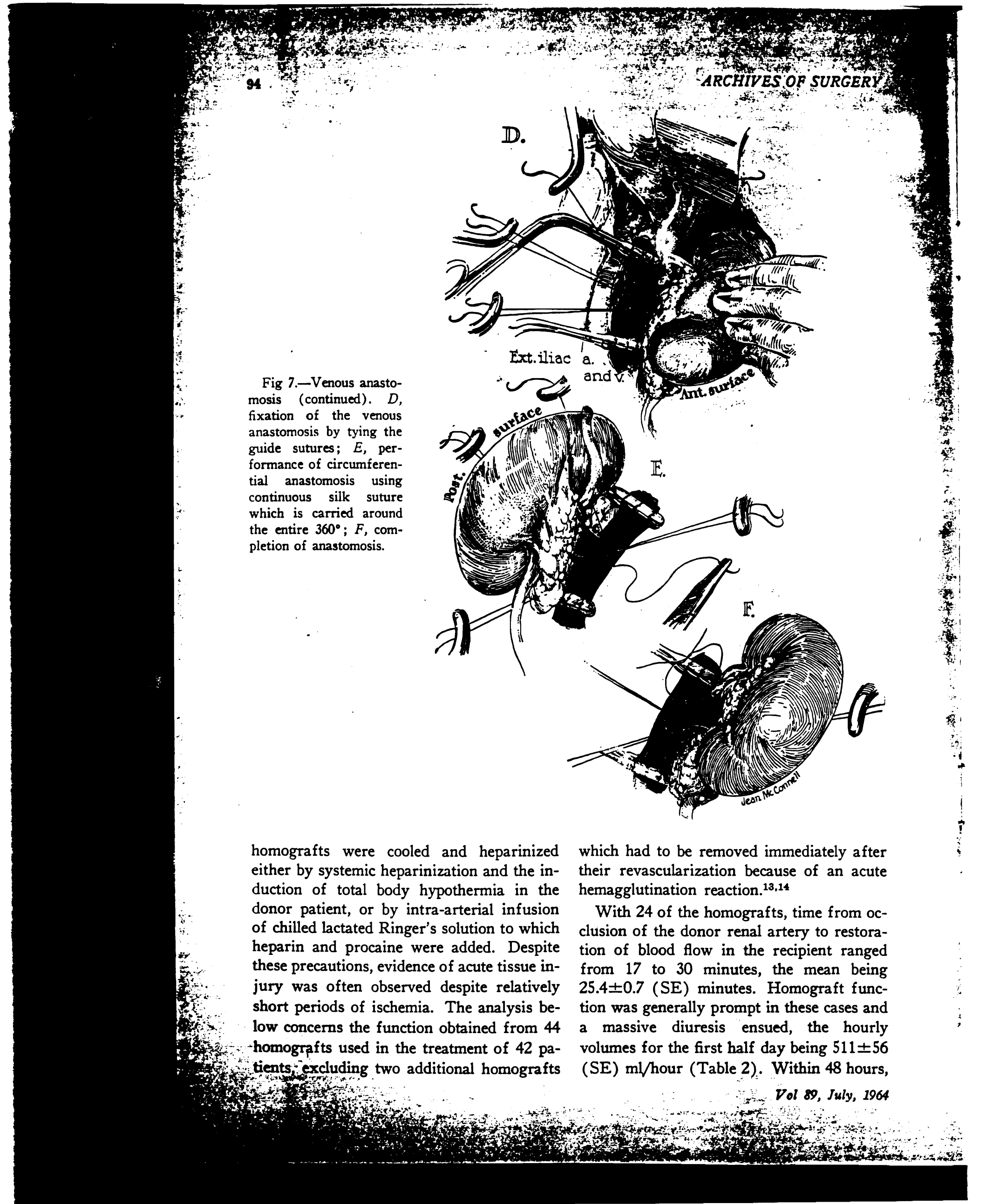




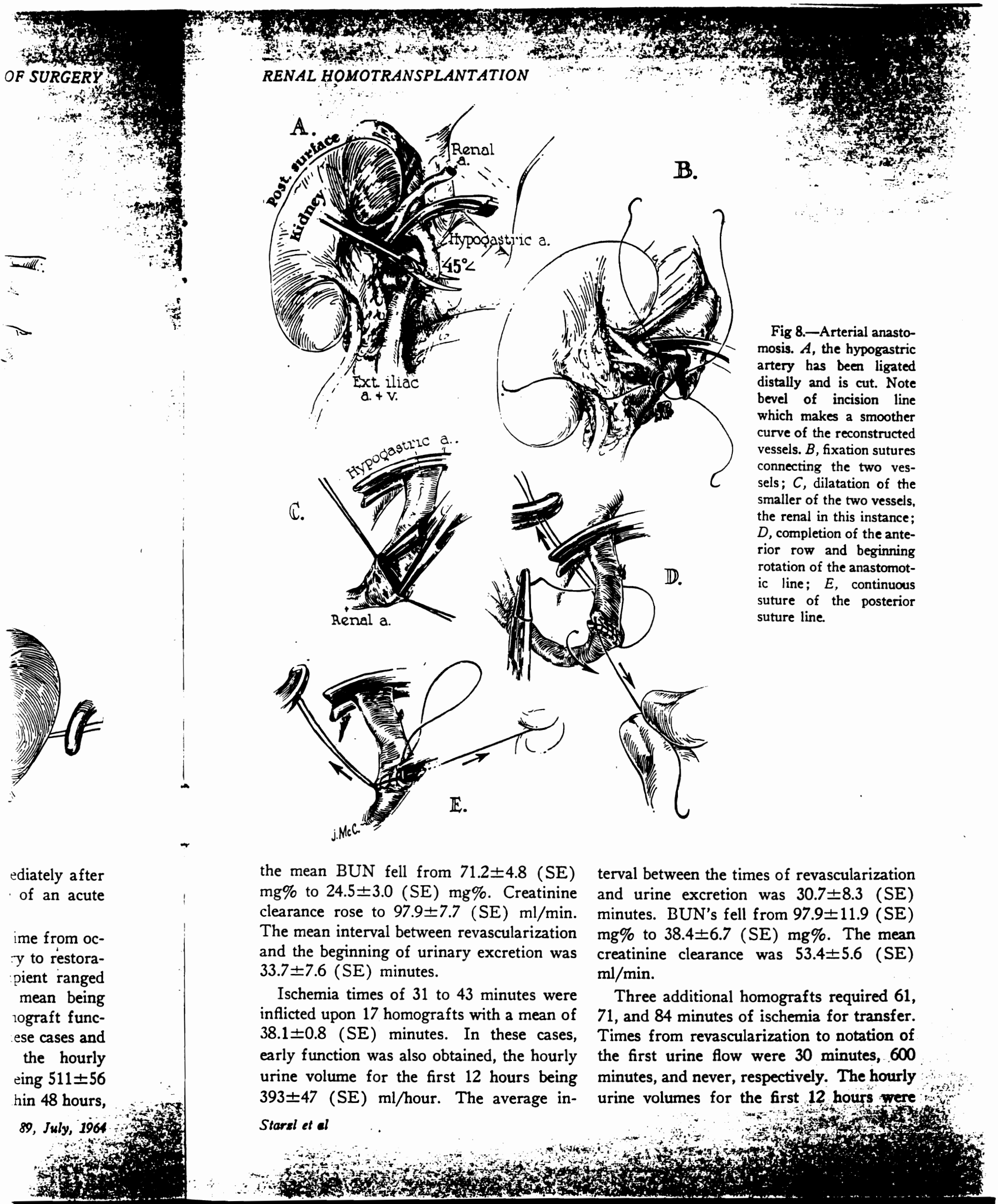




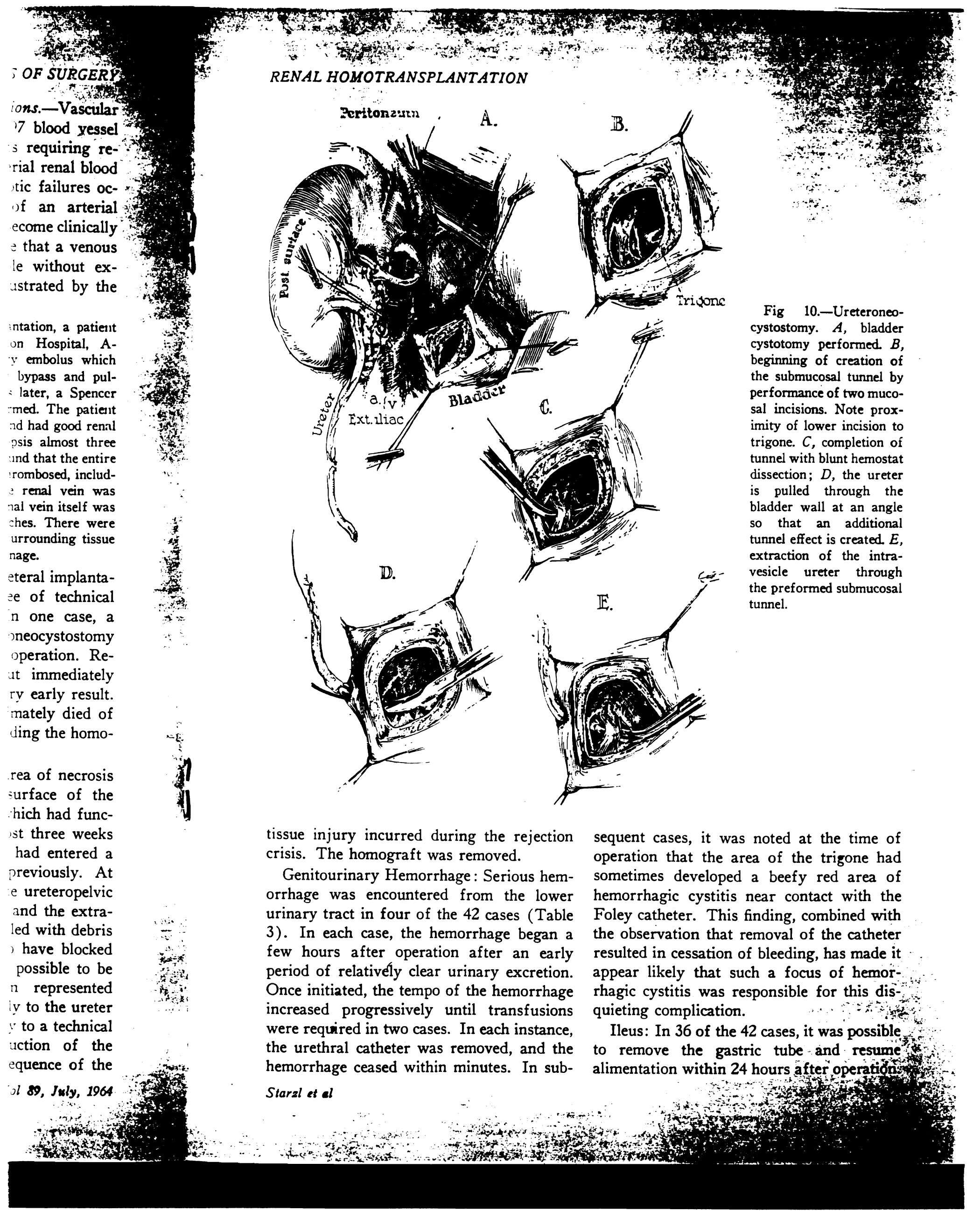



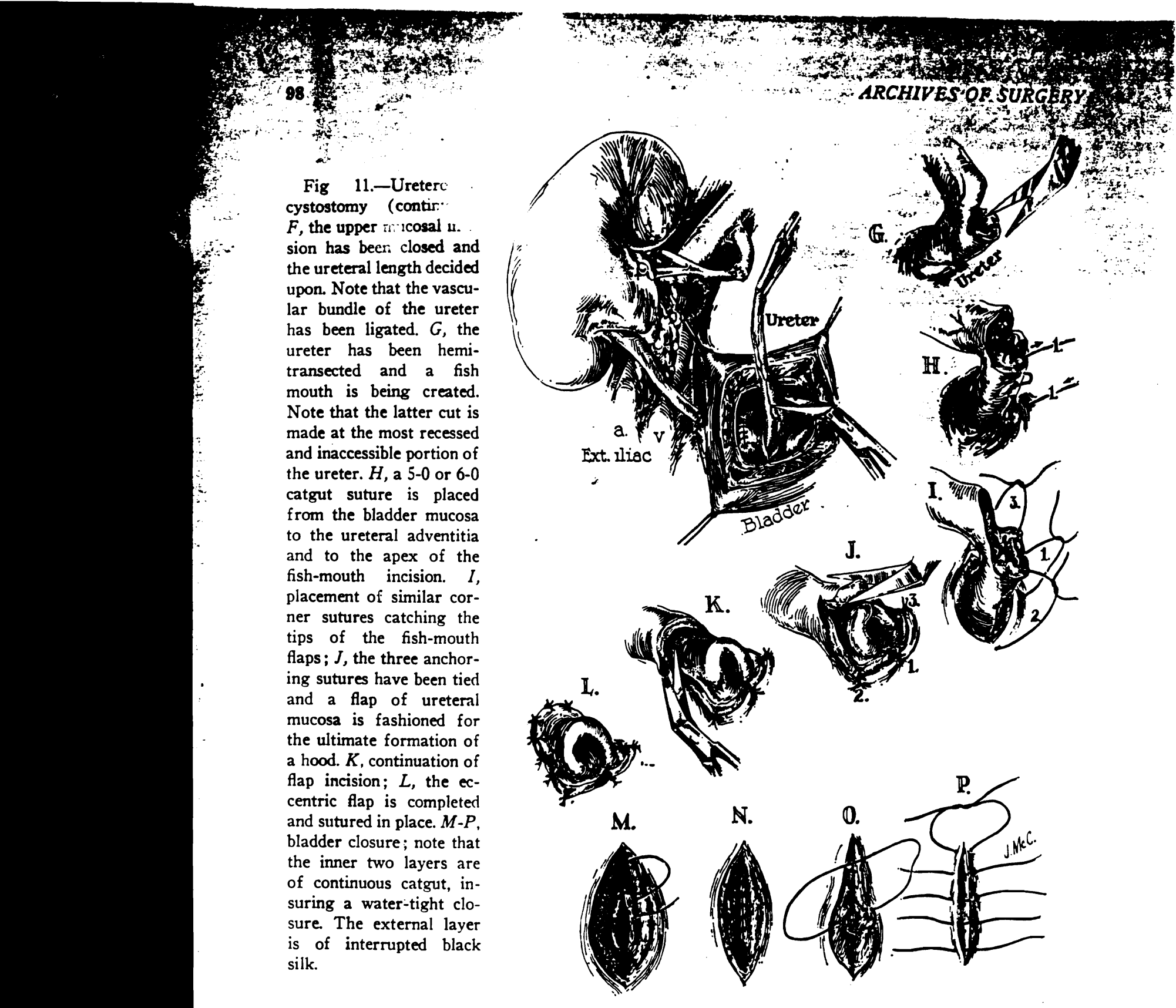

Incision in bladder closed

In the other six, gastric suction was required for two to eight days (Table 3). During this time, therapy with azathioprine was provided with an intravenous solution, ${ }^{17}$ and steroid therapy was given, if required, with intramuscular prednisolone. Two patients had operation for intestinal obstruction, 29 and 32 days after transplantation, both requiring adhesiolysis.

Thromboembolic Complications: Nine patients had clinical evidence of thrombophlebitis during convalescence, and in five of these, the presence of one or more pulmonary emboli was proved either at the time of pulmonary embolectomy or at autopsy. Pulmonary embolization was not the direct cause of death in any of these five patients, and it was recognized clinically in only two instances. In two of the nine patients, heparin therapy was begun but had to be discontinued because of serious hematuria.

Gastrointestinal Hemorrhage: The immunosuppressive regimen employed involves the almost invariable use of large doses of Vol 89, July, 1964 

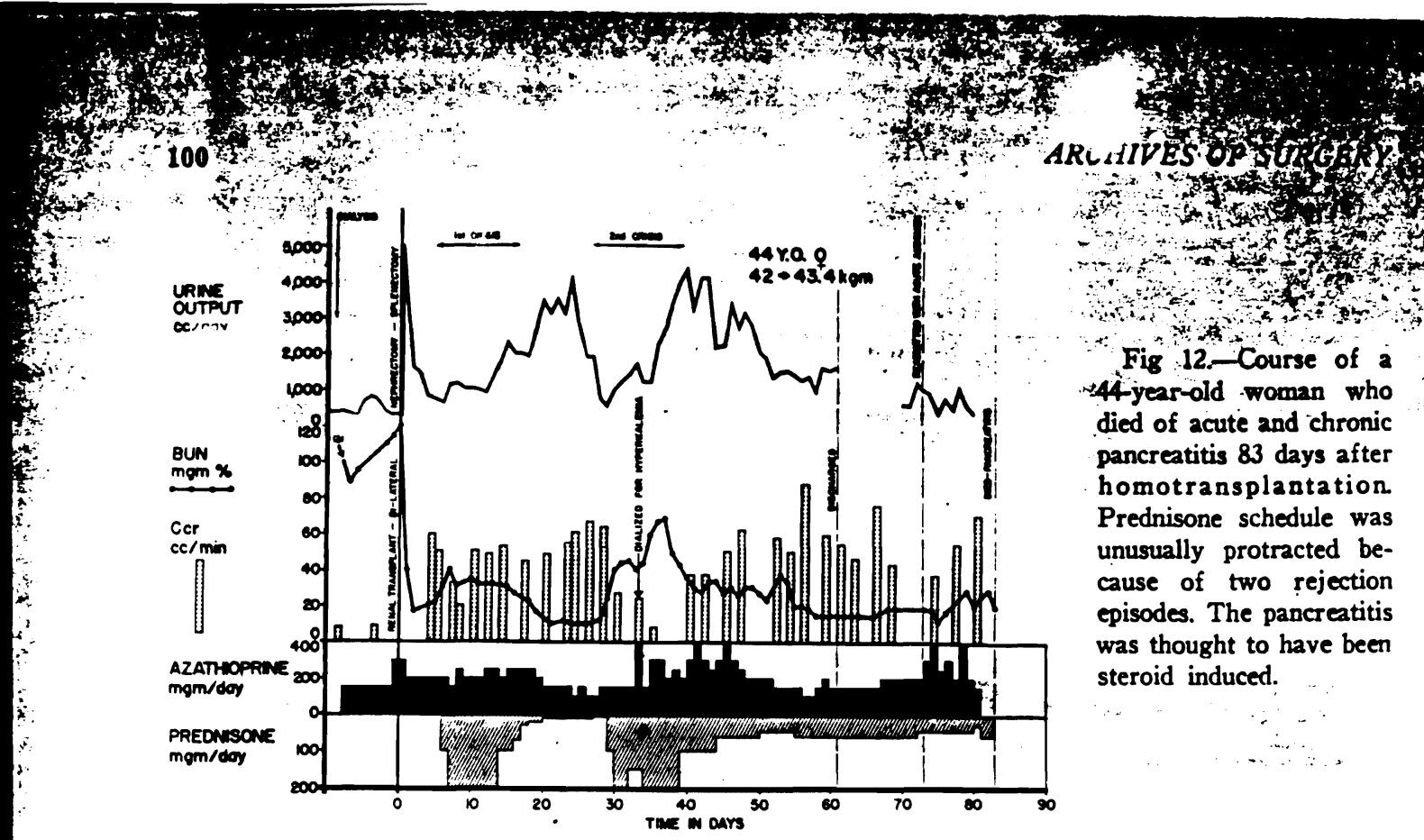

originating in the preoperative period. Advanced neuropathy or myopathy, which were much more common in older patients, proved to be bad prognostic omens. If such changes were severe enough to prevent effective ambulation during the postoperative period, prolonged survival was not attained in a single case. Such bedridden patients frequently developed decubiti, could not eat well, and werre unusually susceptible to drug toxicity.

The relative irreversibility of uremic neuropathy is of interest. Two patients with relatively advanced foot drop have now been followed for 7 and 13 months with almost no improvement. The correction of the original metabolic abnormalities cannot, therefore, restore the neurologically crippled patient to a state of health in the case of advanced neuropathy.

Acute neuropsychiatric disorders such as convulsions, behavioral disorders, or coma occurred both in the pre- and postoperative periods (Table 3 ), and these did not have a grave prognostic significance except when the underlying cause was brain abscess (three cases) or a massive stroke (one case). In two patients with postoperative convulsions, the seizures occurred during the acute posttransplant diuresis, and were probably due to rapid shifts in body water composition. re rapid shifts in body water composition. of arrest during transplantation and died ten s.

days later. Another developed testicular necrosis postoperatively, necessitating orchiectomy. There were two cases of nonfatal hepatitis. Five patients developed postoperative arthralgia which seemed to be related to the use of antihypertensive drugs. One patient had aseptic necrosis of the first lumbar vertebra, necessitating operation for spinal fusion.

Infectious Wound Complications. Failure of primary healing of a wound or subsequent dehiscence, following initial skin healing, occurred at 14 sites in ten patients (Table 4). Staphylococcus aureus, coagulase positive, was involved in nine instances and was accompanied by other pathogens in only one.

TABLe 4.-Clinical Wound Infections in 42 Patients

TABre 4, Chinical Wound Infections in 42 Pedients

Transplant wound

Suparficial

Deep

Controlled Uncontrolled

Thymectomy wound

Suparficial

Deep

Bpleneotomy-Nephrectomy

Buparicial

Deep

Other Founds (deep)

Cardiac arrest, thoracot-

omy wound

Prevloue flant nophrec

tomy

Intestinal obstruotion

$\begin{array}{ccc}8 & 5 & 0 \\ 1 & 0 & 1 \\ 1 & 1 & 0 \\ 1 & 0 & 1 \\ 8 & 3 & 0 \\ 0 & 0 & 0 \\ 1 & 0 & 1 \\ 1 & 0 & 1 \\ 1 & 0 & 1 \\ -14 & 0 & 5\end{array}$




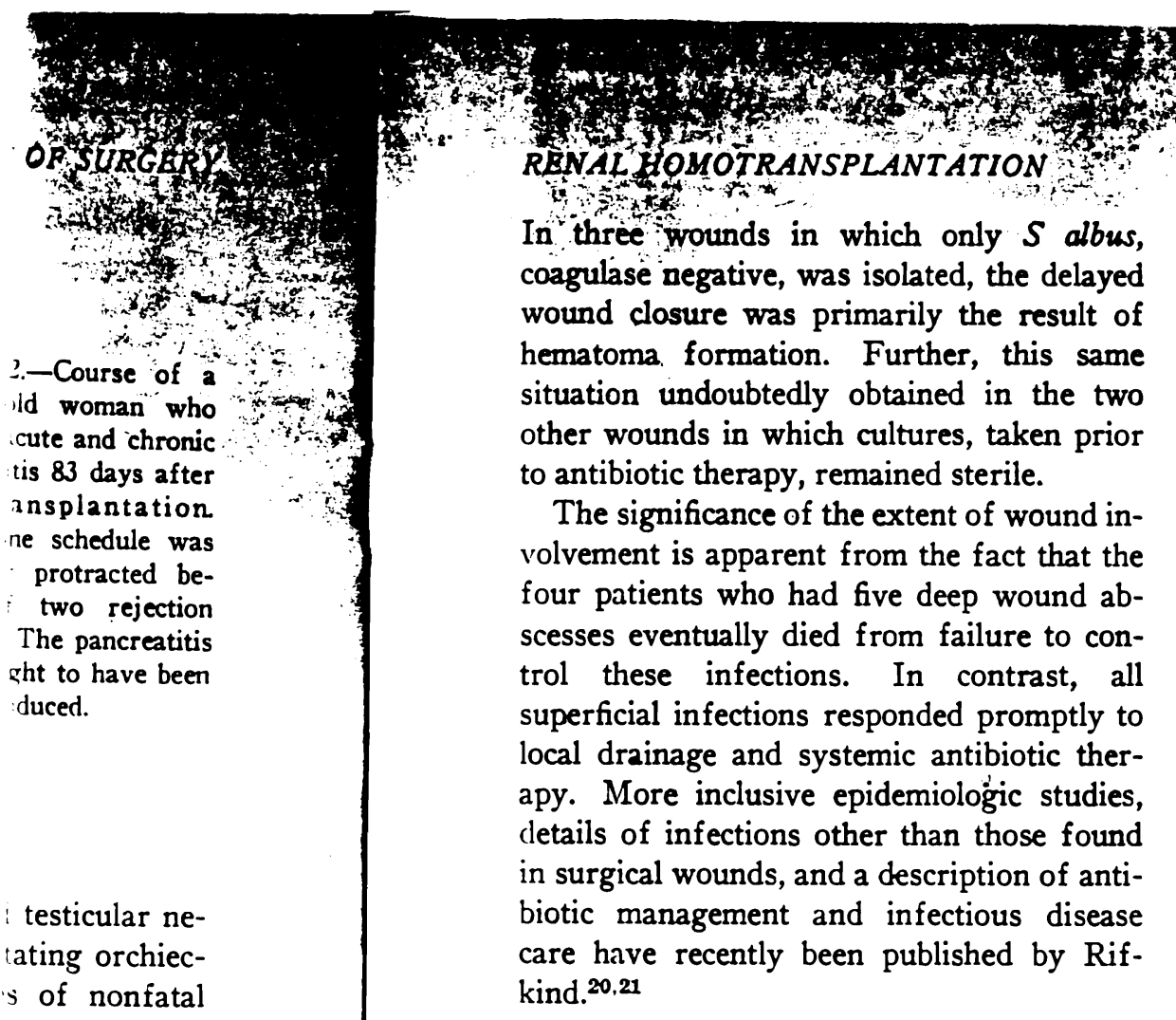

ned postopera-

1) be related to ugs. One pahe first lumbar on for spinal

ttions. Failure or subsequent in healing, ocits (Table 4). ilase positive, $s$ and was ac; in only one.

ns in 42 Patients

lled Uncontrolled

\begin{tabular}{l}
0 \\
1 \\
0 \\
1 \\
0 \\
0 \\
1 \\
1 \\
1 \\
\hline 8
\end{tabular}

PQ, July, 1964

\section{Comment}

Certain complications which have been observed are not unique to renal homotransplantation, but they appear to occur with a much higher frequency in this than in other major surgical procedures. The operation itself and the therapy necessary to achieve chronic function of the homograft impose an increased danger in several pathophysiologic areas.

The cyclic course which follows renal homotransplantation has been fully described elsewhere. ${ }^{4,17,22}$ Briefly, a technically successful operation is followed by a temporary period of good renal function and restoration of well-being. At a varying interval postoperatively, ranging from 1 to 40 days, it has almost invariably been necessary to pass through a rejection crisis, at which time the homograft is threatened with repudiation. The acute illness which occurs at this time, with fever and with evidence of acute functional deterioration of the homograft, can usually be reversed with the addition of massive doses of steroids and actinomycin $C$ to the regimen of azathioprine already in use. Many of the complications which have had probably related to the presence in the retrotheir inception at this critical time are peritoneal space of foreign :tiss under immunologic assault, as wiell pharmacologic agents which must

high doses at this time.
F . xample, the high incidence of gastrointe: al b!ceding was closely related temporally to the rejection crisis. At least two ulcerogenic mechanisms are present at this time. One results from the administration of large doses of prednisone, a drug which is necessary for control and reversal of the rejection process, but which is also a wellknown cause of acute gastrointestinal ulceration. In addition, the secondary uremia which occurs temporarily during this phase of recovery may be an important contributory factor. Fortunately, the gastrointestinal bleeding was controllable in all but one case with conservative measures. In the patient requiring gastric surgery, bleeding was first noted early in the postoperative period, although operation was not ultimately required until six months after transplantation.

In addition to gastrointestinal hemorrhage, other complications are attributable either directly or indirectly to the temporary high dose prednisone therapy. These include the development of moon facies and abnormal fat distribution, steroid-induced diabetes mellitus, osteoporosis or aseptic bone necro$\mathrm{sis}^{23}$ and pancreatitis. ${ }^{18,19}$ One patient (Fig 12), who died of pancreatitis 83 days after operation, had passed through two rejection episodes and had good renal function until the day of death.

The high incidence of thrombotic complications is also of interest. Virtually all the recipients were in the terminal phase of uremia at the time of first consideration of homotransplantation. Their degree of muscle wasting, debility, and inactivity was usually extreme. During the early postoperative period, accentuation of weight loss was frequently seen, some patients losing as much as 50 or $60 \mathrm{lb}$ (22.7 or $27.2 \mathrm{~kg}$ ). Such patients would be expected to have a heightened incidence of thrombophlebitis, after any surgical operation.

With renal transplantation, specific dangers are added. There is the necessity for 


\section{$3 \cdots$

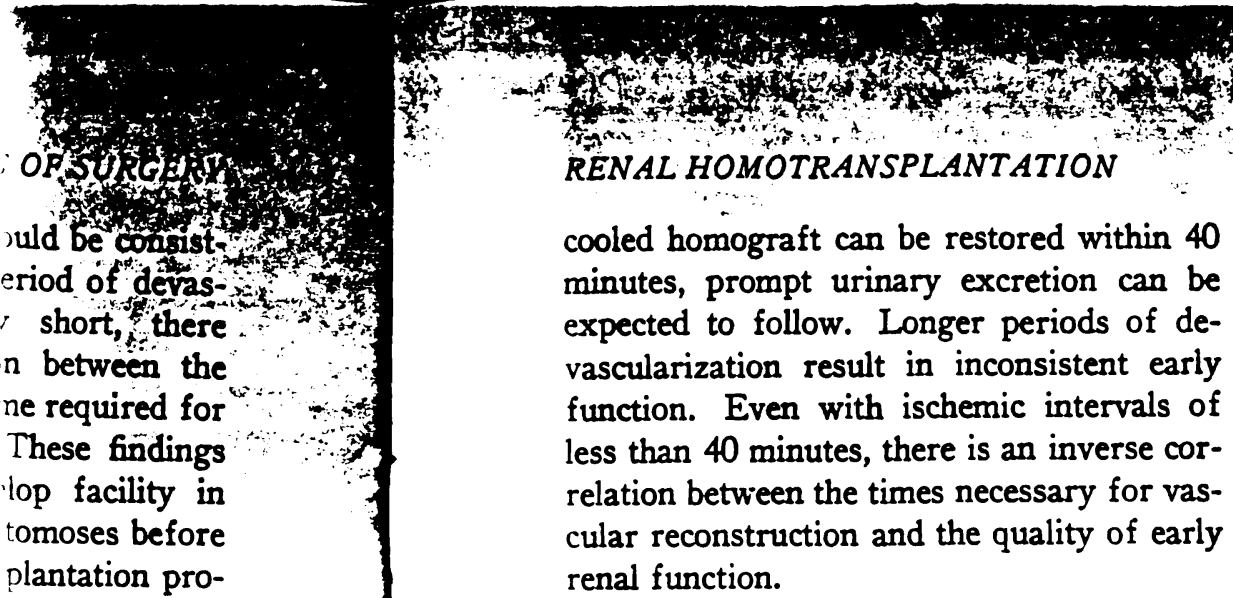

the view that in be obtained be kept to less so suggest that y excretory cathe time ex-

is as a permisit must be em1 of homograft applied in the e was derived. t results would periods under

he reasons for 'motransplantaascribe failure It is important e a significant aase with which and the degree non the transith which comis technical or great as with hout question, ocedures have on in which a initiated and he use of less Icceptance of ntechnical may

tions play a 1 renal homoof homograft supply to the 189, July, 1964
Additional important technical factors involve the site of placement of the homograft, provision for unkinked vascular channels, selection of a method of ureteroneocystostomy which permits early removal of the urethral catheter, avoidance of all drains, and use of a one-stage operation incorporating bilateral nephrectomy and splenectomy in addition to the homotransplantation. The methods by which these objectives are met are described in detail.

Certain postoperative complications which have been observed are not unique to renal homotransplantation, but they appear to occur with a much higher frequency in this than in other major surgical procedures. These include infections, gastrointestinal hemorrhage, diabetes mellitus, pancreatitis, thromboembolism, and neurologic disorders. The high incidence of such complications appears to be due to the high dose immunosuppressive therapy necessary to maintain viability of the homograft during the rejection crisis, to the terminal uremia from which all patients are suffering at the time of operation, and to specific elements of the total operative care such as splenectomy and instrumentation of the pelvic veins.

Thomas E. Starzl, MD, Department of Surgery, University of Colorado Medical Center, Denver, Colo 80220.

\section{Generic and Trade Names of Drugs}

Neomycin-Mycifradin, Myciguent, Neomycin.

Bacitracin-Baciguent, Bacitracin.

Heparin sodium-Heparin sodium, Liquaemin sodium.

Azathioprine-Imuran.

Prednisolone-Delta Cortef, Hydeltra, Meticortelone, Meti-Derm, Paracortol, Sterane, Sterolone. Prednisone-Deltasone, Deltra, Meticorten, Paracort.

Stargl et al
Isophane insulin suspensio Insulin.

\section{Addendumenters}

May 15, 1964.-Twenty-three of thes is $x$ patients who were alive in February are tin th living, all now 6 to 18 months postoperative. is All are residing at home. The single additional death occurred 295 days after homotransplantation as a consequence of late rejection.

\section{REFERENCES}

1. Marchioro, T. L., et al: Use of Extracorporeal Perfusion for Obtaining Postmortem Homografts, Surgery $54: 900,1963$.

2. Starzl, T. E., et al : Renal Transplantation in Identical Twins, Arch Surg 86:600, 1963.

3. Marchioro, T. L., et al : Use of Living Donors for Renal Homotransplantation, Arch Surg 8:711720, 1964.

4. Starzl, T. E., et al: Factors in Successful Renal Transplantation, Surgery, to be published.

5. Starzl, T. E., et al: Splenectomy and Thymectomy in Human Renal Homotransplantation, Proc Soc Exp Biol Med $113: 929,1963$.

6. Starzl, T. E., et al: Technique for Use of Adult Renal Homografts in Children, Surg Gynec Obstet, to be published.

7. Küss, R.; Teinturier, J.; and Milliez, P.: Some Notes on Renal Homotransplantation in Man, Mem Acad Chir (Paris) $77: 755,1951$.

8. Murray, J. E., and Harrison, J. H.: Management of 50 Patients With Kidney Transplants Including 18 Pairs of Twins, Amer J Surg 105:205, 1963.

9. Hume, D. H., et al : Renal Homotransplantation in Man in Modified Recipients, Ann Surg 158: 608, 1963.

10. Starzl, T. E. : Transplantation of the Kidney, Philadelphia: W. B. Saunders Co, 1964.

11. Brown, L.: Vascular Clamp Utilizing Sponge Rubber, Arch Surg $83: 645,1961$.

12. Paquin, A. J.: Ureterovesical Anastomosis: Description and Evaluation of Technique, J Urol $82: 573,1959$.

13. Starzl, T. E., et al: Renal Homografts in Patients With Major Donor-Recipient Blood Group Incompatibilities, Surgery $55: 195,1964$.

14. Starzl, T. E., et al: Incidence, Cause and Significance of Immediate and Delayed Oliguria or Anuria After Human Renal Transplantation, Surg Gynec Obstet 118:819, 1964.

15. Marchioro, T. L., et al : Pulmonary Embolectomy in Patient With Recent Renal Homotransplantation, Surgery $55: 505,1964$.

16. Spencer, F. C., et al: Plication of Inferior Vena Cava for Pulmonary Embolism: Report of 20 Cases, Ann Surg $155: 825,1962$. 


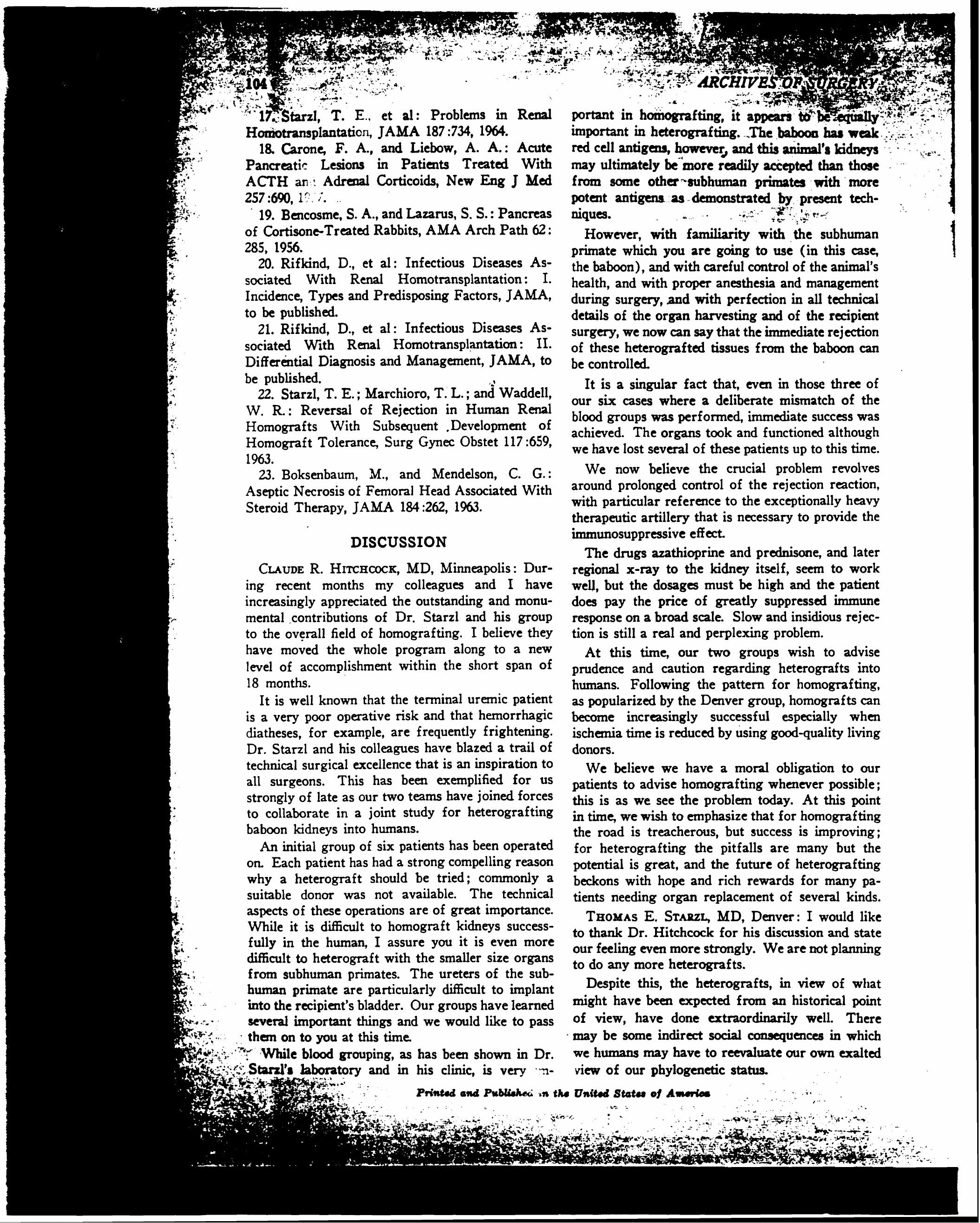

